\title{
Effect of an Educational Program on Nurses' Knowledge about Pediatric Cardiopulmonary Resuscitation in Mosul City Hospitals
}

\author{
Mohammed Attallah Ahmed*
}

Faris Bakir Al-Sawaf **

\begin{abstract}
Background and aim: It is very important that the nurse develop the required knowledge that allows them to assess the patients in emergency situations and perform pediatric cardiopulmonary resuscitation (CPR) when needed both inside and outside hospitals together with the use of the appropriate and correct methods. The purpose of this study is to assess the effect of an educational program on nurses' knowledge about pediatric CPR and determine relationship between nurses' knowledge and demographic information (gender, age, educational level, years of employment, place of work).

Materials and method: A Quasi-experimental study was carried out in Ibn Al-Atheer teaching hospital(study group) and Al-Khansaa Teaching Hospital(control group) in Mosul city from October 28th 2013 to31 December 2014. The study sample was selected randomly consisting of 60 nurses from both hospitals after taking their consent, and the sample was divided into two groups, the study group (30) nurses in Ibn Al-Atheer Teaching Hospital, and the control group (30) nurses in Al-Khansaa Teaching Hospital. (39 male and 21 female).Statistical Package for the Social Science (SPSS), Frequency, Mean, ttest, and ANOVA-one way test was used for data analysis.

Results:The results showed also that the presence of statistically highly significant differences in the knowledge of nurses after implementation of the educational program about pediatric CPR compared to their knowledge in the period preceding the implementation of the program in the study group. The study concluded that the existence of a clear and significant correlation between knowledge about pediatric CPR among nurses and the majority of the demographic characteristics.

Conclusion: the presence of a significant lack in the knowledge of nurses about pediatric CPR before application educational program.
\end{abstract}

Recommendations: The study recommends, preparation, development and implementation of such educational programs in all other Iraqi hospitals.

Keywords: Effect ,educational program, cardio pulmonary resuscitation.

\section{INTRODUCTION}

$\mathrm{CPR}$ is an important medical procedure which is needed for individuals who face sudden cardiac arrest (SCA) to support and maintain breathing and circulation. It is a combination of rescue breathing and chest compressions which are delivered to the victims who are thought to be in cardiopulmonary arrest (American Heart Association, 2010). Life is the most precious possession an individual may have; saving the life of an individual is the most noble thing in the entire world. Nowadays, most deaths occur due to the improper management of a client, especially in a state of emergency. For these reasons, nurses need a specialized form of knowledge in emergency management (European Emergency Nurse, 2011). As nurses are generally the first healthcare professionals in a hospital who realize that the patient is in CA, they must have an adequate level of knowledge and skills in the field of CPR which is a practice based skill (Nicol; Carr; Cleary; and Celenza, 2011). CPR can be performed by health care professionals or by a trained lay person. CPR is used until a person can receive more advanced emergency care performed by health care professionals. Performed immediately, CPR increases a person's likelihood of survival by more than 40 percent (Health gradeinch. WD, 2009). Some pediatric CA's are sudden and unexpected, especially those that occur outside the hospital. Warning signs can be absent or go unrecognized. Pediatric arrests often occur as a complication of, or progression of, respiratory failure, circulatory shock, or both (Sahu; Kishore;and Lata, 2010). According to the (World Health Organization , 2010), in 2008, 17 million people (48\% of all deaths) died from cardiovascular diseases, and mainly because of CA. So, cardiopulmonary resuscitation training is mandatory for nursing staff and is important as nurses often discover the victims of inhospital CA (Hamilton, 2005).

\section{MATERIALS AND METHOD}

A quasi experimental research design with pre and post-test to the (study, control) groups approach was used to evaluate effect of the educational program regarding pediatric $\mathrm{CPR}$ was carried out from (28th October 2013 to 31 December 2014). The study was conducted in

* M.Sc Candidate/ Nineveh Health Directorate.

** Professor/ Nineveh College of Medicine / University of Mosul 
Ibn Al-Atheer and Al-khansaa Teaching Hospitals in Mosul city. A Probability random sample was chosen for the present study. The sample consists of (60) nurses working in both hospitals. They were divided into two groups, each group of (30) nurse who were exposed to the an educational program (study group) in Ibn Al-Athee Teaching Hospital and another group of (30) nurse who were not exposed to the educational program and considered as (control group) in Al-Khansaa Teaching.In order to prepare the assessment tools; a preliminary study was conducted in Ibn Al-Atheer Teaching Hospital on (10) nurses during the period from 11th November up to the 26 of November 2013.The questionnaire is constructed to be introduced to the nurses to evaluate the tools of program upon the nurses demographic information and knowledge which composed of 2 parts. (Part I :Self-administered questionnaire sheet related to demographic characteristics of the nurses. consisted of (5) item which included: Data related to the nurses such as age, gender, educational level and years of employment, and place of work. Part II: Self-administered questionnaire sheet related to nurses' knowledge toward pediatric CPR. It was constructed to assess nurses' knowledge toward pediatric CPR. The tools is mainly based on the information related to the results of the preliminary study and information obtained from literature review. which consists of (50) items for nurses knowledge about pediatric CPR (concepts of pediatric CPR, main steps of pediatric CPR , sign and symptoms of cardiac arrest, recognition of cardiac arrest, meaning and indication for

\section{RESULTS}

Table (1): Distribution of the nurses' Demographic characteristics in the (study and control) groups.

\begin{tabular}{|c|c|c|c|c|c|}
\hline \multirow{2}{*}{\multicolumn{2}{|c|}{ Variables }} & \multicolumn{2}{|c|}{ Study group } & \multicolumn{2}{|c|}{ Control group } \\
\hline & & No. & $\%$ & No. & $\%$ \\
\hline \multirow{3}{*}{ 1- Gender } & Female & 9 & $r$. & Ir & $\varepsilon$ \\
\hline & Male & YI & $v \cdot$ & 11 & 7. \\
\hline & Total & $r$. & $1.0 \%$ & $r$ & $1 \ldots \%$ \\
\hline \multirow{5}{*}{ 2- Age (years) } & $1 \Lambda-Y V$ & $\varepsilon$ & 14 & . & . \\
\hline & $r \Lambda-r V$ & 17 & or & 10 & 0 . \\
\hline & $r \Lambda-\varepsilon \nu$ & V & Tr & 1. & Tr \\
\hline & $\varepsilon \Lambda_{-} O V$ & $r$ & 1. & 0 & IV \\
\hline & Total & $r$. & $1 . \% \%$ & $r$ r. & $1 . . \%$ \\
\hline \multirow{5}{*}{ 3- Educational level } & Secondary Nursing School & $\Lambda$ & tr & $1 T$ & $\varepsilon r$ \\
\hline & Institute of Nursing & 9 & $r \cdot$ & $\mathrm{V}$ & Tr \\
\hline & Bachelor of Science in Nursing & 14 & $\varepsilon r$ & 9 & 30 \\
\hline & $\begin{array}{lll}\text { Postgraduate } & \text { studies } & \text { in } \\
\text { Nursing } & & \\
\end{array}$ & - & - & 1 & $r$ \\
\hline & Total & $r$. & $1 \ldots \%$ & $r$. & $1 . . \%$ \\
\hline
\end{tabular}

CPR, precautions to be taken during CPR, airways, breathing, circulation, complications and nurses' responsibilities in CPR and sequential steps to be followed for giving CPR and up-to-date in CPR). All the items were multiple choice questions, which had 4 alternative responses, a score value of one was awarded to a correct response and zero was allotted for the wrong response .The validity of the program and questionnaire tool was established through a panel of (18) experts of different specialties related to the field of the present study. They were asked respectively to review the questionnaire for clarity and adequacy in order to achieve the present study objective. To evaluate statistically the reliability of instruments, Pearson's coefficient of correlation was used to estimate the scale (test re test) by using SPSS version 19.The study was carried out in Ibn Al-Athee Teaching Hospital which is the place of the study group. The Instructional program was implemented in lecture room in Ibn Al-Athee Teaching Hospital. The final step of the study is to assessment the change that occurs in nurses knowledge in response to the effect of the program . This is done through application of post-test on the study group after three weeks from the implementation of the program. Statistical methods were used in order to assess and analyze the results of the study through the application of descriptive statistics (Frequency, Percentage, Mean, Standard deviation) and inferential statistics (t-test, ANOVA-one way test) by using the Statistical Package for the Social Sciences(SPSS) program version 19. 


\begin{tabular}{|c|c|c|c|c|c|}
\hline \multirow{2}{*}{\multicolumn{2}{|c|}{ Variables }} & \multicolumn{2}{|c|}{ Study group } & \multicolumn{2}{|c|}{ Control group } \\
\hline & & No. & $\%$ & No. & $\%$ \\
\hline \multirow{6}{*}{$\begin{array}{l}\text { 4- Years of work } \\
\text { number of years of } \\
\text { experience }\end{array}$} & Less than 5years & 9 & $r$ & $r$ & $\mathrm{~V}$ \\
\hline & $5-10$ & 9 & $r$. & 9 & $\mu$. \\
\hline & $11-15$ & 7 & $r \cdot$ & 14 & $\varepsilon r$ \\
\hline & $16-20$ & 0 & IV & $r$ & $\mathrm{~V}$ \\
\hline & More than 20 years & 1 & $r$ & $\varepsilon$ & 14 \\
\hline & Total & $r$ & $1 \ldots \%$ & r. & $1 \ldots \%$ \\
\hline \multirow{9}{*}{$\begin{array}{l}\text { 5- Work site place of } \\
\text { work / ward }\end{array}$} & Emergency ward & 0 & IV & 7 & $r \cdot$ \\
\hline & Pediatric ward & 7 & $r \cdot$ & $\varepsilon$ & $\pi$ \\
\hline & Intensive care unit & 0 & IV & 0 & IV \\
\hline & Surgery ward & $r$ & 7 & 1 & $r$ \\
\hline & Operation Room & $r$ & 1. & $r$ & 1 . \\
\hline & Premature unit & $r$ & 1. & 0 & IV \\
\hline & Blood disease ward & $r$ & 1. & . & . \\
\hline & Other & $r$ & 1. & 7 & r. \\
\hline & Total & $r$ & $1 . . \%$ & $r$. & $1 . . \%$ \\
\hline
\end{tabular}

Table (2): Comparison between pre test scores for study and control groups regarding Pediatric CPR knowledge by using t-test at $P$-value $\leq 0.05$.

\begin{tabular}{|l|c|c|c|c|c|c|c||}
\hline \multirow{3}{*}{ Knowledge } & Group & No. & Mean & S.D & T cal. & T tab. & Sig. \\
\cline { 2 - 8 } & Study & 30 & 18.8000 & 4.22146 & \multirow{2}{*}{0.920} & \multirow{2}{*}{2.002} & \multirow{2}{*}{0.721} \\
\cline { 2 - 8 } & Control & 30 & 19.8667 & 4.74693 & \\
\hline \multirow{2}{|l|}{ DF= 58,$\alpha=0.05$}
\end{tabular}

Table (3): Comparison between post-test scores for study and control groups regarding Pediatric CPR knowledge by using t-test at P-value $\leq 0.05$.

\begin{tabular}{||l|c|c|c|c|c|c|c||}
\hline \multirow{3}{*}{ Knowledge } & Group & No. & Mean & S.D & T cal. & T tab. & Sig. \\
\cline { 2 - 8 } & Study & 30 & $\mathbf{4 0 . 8 6 6 7}$ & $\mathbf{3 . 7 2 9 9 7}$ & \multirow{2}{*}{18.521} & \multirow{2}{*}{2.002} & \multirow{2}{*}{0.000} \\
\cline { 2 - 8 } & Control & $\mathbf{3 0}$ & $\mathbf{2 0 . 0 6 6 7}$ & $\mathbf{4 . 8 9 1 4 7}$ & \\
\cline { 2 - 3 } & DF=58, $\alpha=\mathbf{0 . 0 5}$ \\
\hline
\end{tabular}

Table (4): Association between post-test knowledge scores concerning Pediatric CPR with gender of the study group by using t-test at $P$-value $\leq 0.05$.

\begin{tabular}{|c|c|c|c|c|c|c|c|}
\hline \multirow{4}{*}{ Knowledge } & Gender & No. & Mean & $\overline{\text { S.D }}$ & T cal. & T tab. & Sig. \\
\hline & Male & 21 & 41.3333 & 4.17532 & \multirow{2}{*}{1.049} & \multirow{3}{*}{2.002} & \multirow{3}{*}{0.303} \\
\hline & Female & 9 & 39.7778 & 2.22361 & & & \\
\hline & \multicolumn{5}{|c|}{$\mathrm{DF}=\mathbf{2 8}, \alpha=0.05$} & & \\
\hline
\end{tabular}

Table (5): Analysis of variance of nurses' knowledge post test scores regarding age of study group at $P$-value $\leq 0.05$.

\begin{tabular}{|c|c|c|c|c|c|c|}
\hline \multirow{4}{*}{ Knowledge } & Source of variance & S.S & DF & Mean Square & $\mathbf{F}$ & Sig. \\
\hline & Between Groups & 77.336 & 3 & 25.779 & \multirow{3}{*}{2.055} & \multirow{3}{*}{0.131} \\
\hline & Within Groups & 326.131 & 26 & \multirow{2}{*}{12.543} & & \\
\hline & Total & 403.467 & 29 & & & \\
\hline
\end{tabular}

Table(6): Analysis of variance of nurses' knowledge post test scores regarding level of education of study group at $P$-value $<0.05$.

\begin{tabular}{|c|c|c|c|c|c|c|}
\hline \multirow{4}{*}{ Knowledge } & Source of variance & S.S & DF & Mean Square & $\mathbf{F}$ & Sig. \\
\hline & Between Groups & 233.822 & 2 & 116.911 & \multirow{3}{*}{18.607} & \multirow{3}{*}{0.000} \\
\hline & Within Groups & 169.644 & 27 & \multirow{2}{*}{6.283} & & \\
\hline & Total & 403.467 & 29 & & & \\
\hline
\end{tabular}


Table (7): Analysis of variance of nurses' knowledge post test scores regarding duration of experience /years of study group at $P$-value $\leq 0.05$.

\begin{tabular}{|c|c|c|c|c|c|c|}
\hline \multirow{4}{*}{ Knowledge } & Source of variance & S.S & DF & Mean Square & $\mathbf{F}$ & Sig. \\
\hline & Between Groups & 135.211 & 4 & 33.803 & \multirow{3}{*}{3.150} & \multirow{3}{*}{0.032} \\
\hline & Within Groups & 268.256 & 25 & \multirow{2}{*}{10.730} & & \\
\hline & Total & 403.467 & 29 & & & \\
\hline$P=\leq 0.05$ & & & & & & \\
\hline
\end{tabular}

Table (8): Analysis of variance of nurses' knowledge post test scores regarding place of work /ward of study group at $P$-value $\leq \mathbf{0 . 0 5}$.

\begin{tabular}{|c|c|c|c|c|c|c|}
\hline \multirow{4}{*}{ Knowledge } & Source of variance & S.S & DF & Mean Square & $\mathbf{F}$ & Sig. \\
\hline & Between Groups & 180.567 & 7 & 25.795 & \multirow{3}{*}{2.546} & \multirow{3}{*}{0.044} \\
\hline & Within Groups & 222.900 & 22 & \multirow{2}{*}{10.132} & & \\
\hline & Total & 403.467 & 29 & & & \\
\hline$=\leq 0.05$ & & & & & & \\
\hline
\end{tabular}

\section{DISCUSSION}

\section{Demographic Characteristics of the Sample}

Throughout the course of data analysis, it was stated that more than two thirds of the study sample were males $(70 \%)$ in the study group and $60 \%$ in the control group (Table :1) MiddleEastern countries, especially Arab societies, follow some special habits, traditions, and beliefs which oblige females to be as far away as possible from nursing. These results are consistent with other studies that were conducted in Baghdad City by Badir, R and (AlAni.B , 2012), who found that $60 \%$ of their study samples were male. In addition, ( Mohamed, S 2009) indicated that $63 \%$ of her study samples were male.

The age group, (28-37 years old) of the study and control groups accounted for the highest proportion $(53 \%, 50 \%)$ respectively (Table:1). The members of this age group are considered young adults, and can provide and perform nursing intervention efficiently and accurately. These results are consistent with another study that was conducted in Baghdad by Badir , R and (Al- Ani, B , 2012), who indicated that $(53.3 \%)$ of their study samples belonged to the age group of 30-39 years.

More than one third of the nurses in the study group had a Bachelor of Science in Nursing (43\%) and more than one third of the nurses in the control group had a Secondary Nursing School degree (43\%) (Table:1). These results are consistent with another study that was conducted in Kirkuk City by ( Hassan, S and Hassan, H, 2012) who indicated that $(42.5 \%)$ of her study samples were graduates from a secondary school of nursing. In addition( Al-
Fattah, 2004), indicated that (48\%) of her study samples had graduated from a secondary school of nursing. Regarding the years of experience, about $30 \%$ of the study samples had less than five years of employment. Another 30\% had 510 years' experience (table: 1$)$. These results are consistent with (Christofer, 2007), who reported that $36 \%$ of his study samples had 1- 4 years' experience and $26 \%$ had 5-8 years' experience. Also about 2/3 of the control group had 11-15 years' experience $(43 \%)$ respectively (Table-1). This finding is in agreement with Parajulee et al. (2011) who stated that $40 \%$ of respondents had 12 years' experience. In addition, (Hickam et al. 2003) claimed that nurses' experience is more important than their educational level. Since most of the nurses who have had many years of service period move away to the primary health sector, so the younger nurses stay in the hospital care (Al-Aklawy, 2013). The sample was distributed almost evenly in all wards/ units of the hospital (Table:1) in study and control group. In the study group, $20 \%$ of the respondents were working in the Pediatric Ward, $17 \%$ in the Emergency Ward and $17 \%$ in the Intensive Care Unit, and 10\% for each of the following: Operation Room , Premature Unit , Blood Disease Ward and other departments. In the control group, $20 \%$ were working in each of the emergency wards and other departments; $17 \%$ were working in each of the Intensive Care Unit and Premature unit; $13 \%$ in the Pediatric Ward; $10 \%$ in Operation rooms and $3 \%$ in Surgery Ward. These results are in agreement with (Christofer ,2007) who found that the nurses working in wards constituted $20 \%$ of the group. $20 \%$ were in emergency 
wards, $23.3 \%$ were in the ICU; $6.7 \%$ were other distributed in special wards.

\section{Nurse's pre and post-test score}

Before the implementation of the educational program, a pre-test was carried out on study and control groups. The study found that there was no significant difference between the two groups regarding pediatric CPR (Table:2), These results corroborate findings from (Hend et al., 2012) who found that nurses' knowledge scores were poor before the training program, but strongly increased after the program. In addition, (Hussain et al. ,2009) stated that the majority of the nurses have poor CPR knowledge before implementation of educational programs. After the implementation of the educational program on the study group, post-test was administered for both groups three weeks after the program. Results indicated that there was a significant difference in the post-test for study group (Table:3). This means that there was significant improvement in their knowledge regarding pediatric CPR. Furthermore, studies by (Meissner ,2012), (Bakhtiar et al., 2007), and (Madden ,2006) showed significantly increased levels in nurses' knowledge post CPR training program.

3.Study of variables of nurses and their effects an educational program in the posttest scores:

Tables (4) showed no significant differences between the post-test scores of pediatric CPR knowledge with regard to gender of nurses. Because the educational program was only about knowledge and not about knowledge and practice maybe there was a significant difference between males and females because performing cardiopulmonary resuscitation needs power that is found in males and not in females. These results agree with those found by ( Blessy, 2011) who reported that there were no significant differences between the post educational program scores regarding CPR knowledge and gender.

Tables (5) show no significant differences between the post-test scores of pediatric CPR knowledge with regard to nurses aged 18-27 years, which may be explained by the fact that younger nurses had recently graduated, were more interested and motivated to learn and much more active than the older ones. This result corroborates findings by (Parajulee and Selvaraj, 2011) who reported that there was no significant association between the total knowledge score and age of the respondents. In addition, (Khudhair ,2011) also stated that based on age difference there were no significant differences between the nurses practice scores on neonatal resuscitation. Table (6) shows a significant difference in nurse's knowledge scores regarding the educational level in post-test of the study group at $\mathrm{P}$-value $\leq 0.05$. This strongly suggests that graduate nurses are better equipped with knowledge with regard to pediatric CPR. The level of education may affect the knowledge of nurses as (Al-Simady, 2006) and (Shayma'a, 2004) have mentioned. This findings corroborate results established by (Hend et al, 2012)who proved that there was a significant correlation between post-test scores and the level of education of nurses. Table (7) showed that there was a highly significant statistical difference in post - test scores between nurses knowledge with regard to their duration of experience /years at $\mathrm{P}$-value $\leq 0.05$ in the study group. This result is explained by the fact that nurses gain experience through their training in the hospital. This result agrees with( Jensen et al. ,2008) who reported that there was a significant statistical difference between the total knowledge score regarding ALS and the duration of experience or number of work years of the respondent. In addition, ( Gohary ,2001) stated that there was an improvement in the level of nurses' knowledge after training programs, combined with the increase in the years of experience. Table (8) showed that there was a significant statistical difference in nurse's knowledge scores regarding place of work /ward in post-test of the study group. For the benefit of nurses working in intensive care units, this increase of nurses experience when dealing with these cases is consistent with the effect of educational level on the knowledge of nurses. Moreover, (Bristow et al. 2000) reported that most cases of cardiac arrest occur in the intensive care unit. This result corroborates (Parajulee's, 2011) findings who discovered a significant difference between knowledge and working area of the respondents. CONCLUSION

On the bases of the objectives of the current study and outcomes of data analysis, the following have been concluded: There is a lack of nurses' knowledge regarding pediatric CPR before implementation of the educational program in pre-test. The effects of the educational program were manifested through the acquisition of the nurses' knowledge after implementation of the program. Significant statistical differences have been found regarding pediatric CPR knowledge in post - test scores for nurses according to the level of education, 
duration of experience, place of work/ward, previous training, and the source of information concerning CPR, but there were no significant statistical differences according to the gender, age, previous attendance to conferences and nurses agreement that the training on CPR should be obligatory.

\section{RECOMMENDATIONS}

Based on the results of the study, the researcher recommends that construction of Pediatric CPR Guidelines for Iraqi hospitals by the Ministry of Health to help nurses acquire the necessary knowledge to deal with pediatric cardiopulmonary arrest. Apply such educational health programs in all Iraqi governorate hospitals. Inclusiveness of adult CPR in such educational health programs. Repetitive periodic CPR training courses to ensure that nurses are competent, up to date, and confident responders in the event of a cardiopulmonary arrest. CPR educational program should be included in all nursing schools and curricula.

\section{REFERENCES}

Al- Fattah, M. (2004). Impact of Quality Improvement programs in Nursing Care on the postoperative complications of Laparoscopic Cholecystectomy. M.Sc.Thesis. College Nursing ,Mosul University. P.p.36.

Al-Aklawy,Y.(2013). Effectiveness of an Educational Program for Nurses About Diabetic Foot Care M.Sc.Thesis, University of Mosul ,College of Nursing. P.p. 65-66.

AL-Simady, A. (2006). Assessment of Nursing Knowledge and Practice concerning Cardiogenic Shock, University of Mosul, MSc Thesis. P.p. 74.

American Heart Association (AHA). (2010). Guidelines for CPR and ECC Executive Summary of (AHA). P. p.27.

Badir, R, ; and Al- Ani, B; (2012). "Impact of an Educational Program upon Nurses' Knowledge and Practices Concerning Neurogenic Bladder Rehabilitation for Spinal Cord Injured Persons", University of Baghdad, College of Nursing. Iraqi National Journal of Nursing Specialties. 25 (2). P.p. 74.

Bakhtiar, A.; Maziar, Z. (2007). "Narrative review: Cardiopulmonary resuscitation and emergency cardiovascular care: Review of the current guidelines".
Annals of Internal Medicine. 147. P.p. 171-179.

Blessy, J.(2007). Assess the Effectiveness of Structured Teaching Programs on Knowledge and Skills regarding CPR among students of selected arts and science college, Bangalor. Rajiv Gandhi University of Health Sciences M.Sc.Thesis. P.p.38-39.

Bristow, P.; Hillman, K.; Chey, T.; Daffurn, K.; Jacques, T.; Norman, S. Bishop, G.; Simmons, EG. (2000). Rates of inhospital arrests, deaths and intensive care admissions: the effect of a medical emergency team. US National Library of Medicine National Institutes of HealthSep. 173(5). P.p.236-240.

Christofer , D. (2007). Assess the effectiveness of structured teaching programs on knowledge and skills of CPR among nurses working in selected hospitals. M.Sc.Thesis Rajiv Gandhi University of Health Sciences;pp. 44-78 .

European Emergency Nurse. (2011). EuSEN enewsletter. ( $3^{\text {rd }}$ edition).

Gohary A. (2001). Nurses' performance concerning control of patient with pulmonary tuberculosis. Master thesis. Faculty of Nursing, Ain Shams University.

Hamilton, R; (2005). "Nurses knowledge and skill retention following cardiopulmonary resuscitation training: a review of the literature". Journal of Advanced Nursing. 51.P.p. 288-97.

Hassan, S.; and Hassan , H; (2012). "Effectiveness of nursing education program on nurses knowledge toward Arrhythmia in Kirkuk's teaching hospitals". College of Nursing, University of Kirkuk.. Kufa Journal for Nursing Sciences 2(3). P.p. 56-64.

Health gradeinch. WD. (2009, April18). Wrong diagnosis Statistics about cardiac arrest Available from http//www.wrongdiagnosis.com.

Hend, M. Elazazay; Amany L. Abdelazez; and Omibrahem A. and Elsaie, J. (2012). "Effect of Cardiopulmonary Resuscitation Training Program on Nurses Knowledge and Practice". Life Sci J. 9(4). P.p. 3464-3466.

Hickam, DH.; Severance, S.; Feldstein, A.; et. $a$ l. (2003). The Effect of Health Care Working Conditions on Patient Safety. Rockville, Md: Agency for Healthcare 
Research and Quality. Evidence Report/ Technology Assessment AHRQ publication. 74. 03-E031.

Hussain, M.; and Lyneham, J. (2009). Cardiopulmonary resuscitation knowledge among nurses who work in Bahrain. International Journal of Nursing Practice. 15 (4). P.p. 294-302.

Jensen, M; Lippertb, F.; Hesselfeldt, R. F. (2009). "The significance of clinical experience on learning outcome from resuscitation training: A randomized controlled study.CentreforClinicalEducation, Copenhagen University Hospital, Rigshospitalet, Denmark". Resuscitation. ( 80). P.p. 238-243.

Khudhair, S. (2011). Evaluation Nurses' Practices toward Neonatal Resuscitation in the Delivery Room. College of Nursing, University of Baghdad. P.p.66-67.

Madden, C. (2006). "Undergraduate nursing student's acquisition and retention of CPR knowledge and skills". Nurse Education Today. 26. P.p. 218.

Meissner, T.; Kloppe, C.; Hanefeld C. (2012). "Basic life support skills of high school students before and after resuscitation training: a longitudinal investigation". Scandia Journal of Trauma Rhesus Emergency Medical. 20. P.p. 31.
Mohamed,S. (2009). Effectiveness of Educational Program on Nurses Knowledge and Practices Toward Skin Care and Prevention of Pressure Ulcer for Spinal Cord Injured Persons. Ph. D. dissertation, College of Nursing. University of Baghdad. P.p.118.

Nicol, P.; Carr, S.; Cleary, G.; and Celenza, A. ( 2011). "Retention into internship of resuscitation skills learned in a medical student resuscitation program incorporating an immediate life support course". Resuscitation. 82. P.p. 45-50.

Parajulee, S.; Selvaraj, V. (2011). "Knowledge of nurses towards cardiopulmonary resuscitation in a tertiary care teaching hospital in Nepal". Journal of Clinical and Diagnostic Research. 5(8). P.p. 1585-1588.

Sahu, S.; Kishore, K.; and Lata., I. (2010). "Better outcome after pediatric resuscitation is still a dilemma". $J$ Emerg Trauma Shock. 3(3). P.p. 43-50.

Shayma'a, N. (2004). Nursing Role During Magnetic Resonance Imaging. University of Mosul, un published MSc Thesis. P.p. 60.

World Health Organization. (2010). Available from http:// www.who. int/ghoncd /mortality _ morbidity /en/. 